\title{
Changes in the Respiratory System of Rats Exposed to the Herbicide Paraquat
}

\author{
${ }^{1 *}$ Daniel Silveira Serra, ${ }^{2}$ Renato Silva Pinheiro, ${ }^{3}$ Gilvan Ribeiro dos Santos, \\ ${ }^{4}$ Natannael Almeida Sousa, ${ }^{5}$ Fladimir de Lima Gondim, ${ }^{6}$ Rinaldo Santos Araújo, \\ ${ }^{7}$ Mona Lisa Moura de Oliveira, ${ }^{8}$ Francisco Sales Ávila Cavalcante \\ ${ }^{1 *}$ Institute of Biomedical Sciences, State University of Ceará, Ceará, Brazil. Av. Dr. Silas Munguba, \\ Fortaleza-Ceará, Brazil. \\ ${ }^{2,3,4,7,8}$ Center of Technological Sciences, State University of Ceará, Ceará, Brazil; \\ ${ }^{5}$ Institute of Biomedical Sciences, State University of Ceará, Ceará, Brazil; \\ ${ }^{6}$ Department of Chemistry and Environment, Federal Institute of Ceará, Ceará, Brazil
}

\begin{abstract}
The use of herbicides is constantly being adopted in developing countries who need to increase productivity in the agricultural sector. The world market for herbicides grew 39\% between 2002 and 2011 and predicted a growth of $11 \%$ in 2016. The Paraquat ${ }^{\circledR}$ is herbicide with biological activity used worldwide. The present work had as objective to examine the respiratory system of rats exposed to paraquat. Wistarrats, with body weight of $225 \pm 25 \mathrm{~g}$ were used in this study. The animals were randomly divided into three groups, a group in which it was administered of saline $(C)$, other group were administered paraquat to $10 \mathrm{mg} / \mathrm{kg}(P 10)$, and a third group was administered paraquat to $30 \mathrm{mg} / \mathrm{kg}(P 30)$, intraperitoneally. All concentrations used are considered environmentally relevant. The values of the airway resistance $\left(R_{N}\right)$, tissue elastance $(H)$, tissue resistance $(G)$ and hyperresponsiveness of the airway smooth muscles of the animals, were statistically significant. In conclusion, ours results demonstrated the harmful character that exposure to paraquat can cause in the respiratory system of rats. More detailed studies are required that can quantify the level of exposure that the population undergoes when eating some foods, which may present remnants of this pesticide in its composition.
\end{abstract}

Keywords: paraquat, respiratory system, exposure, herbicide.

\section{INTRODUCTION}

The world agricultural pesticide industry was transformed by several years of growth. According to the Union of manufacturers of agrochemicals from Brazil, between the years 2000 and 2010, the sale of pesticides in the world grown 96.7\%, and in Brazil, this growth was $189.6 \%$. In the period from 2006 to 2011, sales of agrochemicals increased on average $72 \%$ and between the main classes of products, sales of fungicides to combat diseases such as soybean rust has tripled, while the insecticide advanced $84 \%$ and the herbicides, $44 \%$.(TUIAP, 2012).

Agricultural herbicides are composed of biological activity of extreme importance for the food industry worldwide (Sphefeson et al. 2006). These are among the most common pesticides (Chan et al., 2007) and your use is growing worldwide, mainly in developing countries (Gianessi, 2013). The world market for herbicides grew 39\% between 2002 and 2011, and predicted a growth of $11 \%$ in 2016. The use of herbicides is constantly being adopted in developing countries need to increase productivity in the agricultural sector (Zhang, 2003).

Studies evidencedthat some herbicides pose a potential risk for humans and other life forms, in addition to harmful effects to the environment (Forget, 1993). The poisoning by herbicides and other chemicals used in agriculture, represents a public health problem throughout the world. More than 20,000 deaths and 2 million hospitalizations occur annually due to poisoning with pesticides and chemicals used for agriculture (Khalighi et al., 2016).Dermal exposure or by spraying, is usually associated with only limited and localized lesions. However, accidental or deliberate ingestion, results in an extremely high mortality rate, and can cause local irritation of the mouth, oropharynx and esophagus and multiple organ failure (cardiac, respiratory, liver and kidney) (Chao et al., 2016). 
Among the most widely used agricultural herbicides, paraquat (1.1-dimethyl -4.4'bipyridyl dichloride) (Figure 1), a fast-acting herbicide and low cost (Gunnel et al., 2007) which is commonly applied in cotton, rice, banana, coffee, sugar cane, corn, soybeans and others (NHSA, 2010). The use of paraquat contributes to maintaining a weed flora, because defeat only the growth of the aerial part and does not affect the germination of new seedlings, thus, the vegetation if reset (Martins, 2013).

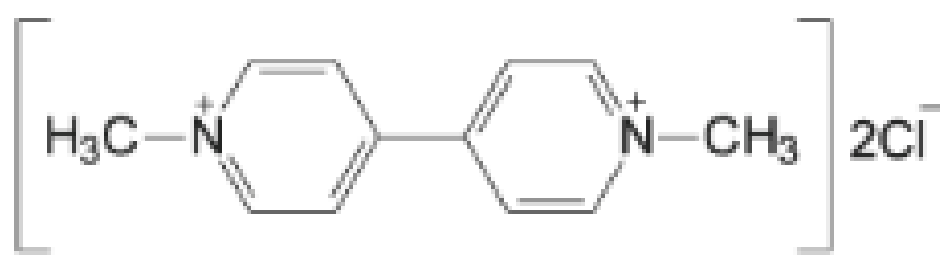

Fig1. Chemical structure of paraquat

Paraquat is manufactured by several countries, such as China, USA, Italy and United Kingdom, and in most countries, the raw material is imported and the formulation of the product shall be made on site (Serra et al., 2003). Occupational exposure to paraquat does not entail any danger to health if it is managed safely, however, the number of cases of poisoning is hight, voluntary or accidental (Serra et al., 2003).

Reports carried out in countries using paraquat in the agricultural sector have shown that paraquat poisoning presents a mortality rate between $50 \%$ and $90 \%$, representing $13 \%$ of all cases fatal (Cha et al., 2014). The Japan has registered significant numbers of deaths arising from exposure to paraquat, more than 1000 per year, whereas in Ireland the mortality reaches 78\% and in Costa Rica, 60\% (Xarau et al., 2000).

The toxicity of paraquat affects lungs, kidneys, liver, pancreas, heart and nervous system, being the most affected lungs (Naito et al., 1987; Serra et al., 2003). The lungs are the main target organs of paraquat, leading to severe injury and fibrosis, causing epithelial cellular injury due to your action on type I and type II pneumocytes in addition to edema, hemorrhage, infiltration of inflammatory cells and cellular espações (Rocco et al., 2004; Samson et al., 2006; Choi et al., 2013), however, the oxidative stress plays a crucial role in the pathogenesis of paraquat-induced lung injury (Tian et al., 2014).

In view of the above, and for being the lung, one of the organs most affected by paraquat, the present work had as objective to examine the respiratory system of rats exposed to paraquat (1.1-dimethyl -4.4 'bipyridyl dichloride), in an attempt to aggregate knowledge about the real health risks that farmers are submitted by exposure to agricultural products containing paraquat as an active ingredient.

\section{MATERial AND MethodS}

\subsection{Animals}

This study followed all the regulations in force for the maintenance of good animal welfare. All protocols used were previously approved by the Commission on ethics to the use of animals from the Universidade Estadual do Ceará (Protocol No 12237681/28).

Albino rats, Rattus novergicus, Wistar variety, female, with body weight of $225 \pm 25 \mathrm{~g}$ were used in this study. The animals were randomly divided into three groups. A group in which it was administered $0.2 \mathrm{~mL}$ of saline (i.p.), known as Group $\mathrm{C}(\mathrm{n}=8)$. In the other group were administered paraquat to $10 \mathrm{mg} / \mathrm{kg}$ diluted in saline solution $0.2 \mathrm{~mL}$ (i.p.), called P10 Group $(\mathrm{n}=8)$. And a third group was administered paraquat to $30 \mathrm{mg} / \mathrm{kg}$ diluted in saline solution $0.2 \mathrm{~mL}$ (i.p.), called Group P30 $(n=8)$. All concentrations used are considered environmentally relevant.

\subsection{Experimental Protocol}

24 hs after administration of saline solution (C) or paraquat (P10 and P30), the animals were anesthetized with sodium pentobarbital $\left(30 \mathrm{mg} / \mathrm{kg}\right.$, Hypnol ${ }^{\circledR} 3 \%$, Syntect, Brazil) intraperitoneally, and undergoing tracheotomy for the insertion of a cannula of 14 gauge (Eastern medikit LTD.) which was secured to the trachea. The cannula was then connected to a ventilator for small animals (Scirec ${ }^{\odot}$ flexVent ${ }^{\circledR}$ ) computer controlled. The animals were ventilated in basal patterns at a frequency of $90 \mathrm{breaths} / \mathrm{min}$, a tidal volume of $10 \mathrm{~mL} / \mathrm{kg}$, with pressure limit of $30 \mathrm{cmH}_{2} \mathrm{O}$ positive end-expiratory pressure (PEEP) of $3 \mathrm{cmH}_{2} \mathrm{O}$. 
So that the lung function variables were collected from reliable way, it is necessary that the animal is sufficiently sedated and paralyzed so there's no interference of their respiratory muscles. To this end, the vents Pancuronium bromide $\left(0.5 \mathrm{~mL} / \mathrm{kg}\right.$, Pancuron ${ }^{\circledR}$, Cristália, Brazil $)$ was administered intraperitoneally.

Pulmonary function analyses were performed after waited five minutes for the animal accommodation, verification of possible leaks, obstructions, fixes the position of the animal in relation to the fan and the confirmation that the animal was not performing spontaneous inspirations. Initially proceeded to the standardization of mechanical conditions of the respiratory system with two deep inflation (IP) with pressure limit of $30 \mathrm{cmH}_{2} \mathrm{O}$ and $6 \mathrm{~s}$ duration. To reduce the effect caused by broncoprotetor IP's (Kapsali et al., 2000) the animals were ventilated by a 20 minute period on basal patterns.

Soon after, the impedance of the respiratory system $\left(Z_{r s}\right)$ was measured by forced oscillation technique in sequence at intervals of $30 \mathrm{~s}$ during 6 minutes. The $Z_{r s}$ wasdetermined by measuring the volume and pressure of the piston in the cylinder while fan 3 disturbances of oscillatory volume were delivered to the airway. These disturbances were carried through overlapped sine waves 13 with changes in amplitude and frequency $(1-20.5 \mathrm{~Hz})$. The frequencies were fixed in mutually conditioned values to reduce harmonic distortion that can occur in non-linear systems (HANTOS et al., 1992).

Before the start of the protocol was obtained necessary dynamic calibration signals to compensate for mechanical ventilator influences in subsequent measurements $Z_{r s}$. The $Z_{r s}$ was determined by Fourier transform of signals of piston fan volume and pressure of the cylinder as described previously (Hirai et al., 1999). The $Z_{r s}$ was adjusted to constant phase model (Eq. 1 and 2):

$Z_{r s}=R_{N}+I(2 \pi f) i+\frac{G-H i}{(2 \pi f)^{\alpha}}$

with,

$\alpha=\frac{2}{\pi} \tan ^{-1}\left(\frac{H}{G}\right)$

Where: $R_{N}$ represents the Newtonian resistance, related central airway resistance, $i=\sqrt{-1}, f$ is the frequency $(\mathrm{Hz}), I$ is the inertance of the airways, and $G$ and $H$ respectively feature the dissipative and elastic properties of the lung tissue (Hantos et al., 1992).

\subsection{Acetylcholine Dose-Responsecurve}

For the analysis of the hiperresponsividade of the smooth muscle of the Airways, soon after the analysis of the mechanics of the respiratory system, we collected data on the dose-response curve to acetylcholine $(\mathrm{ACh})$. At the beginning of this protocol, in sequence, the mist of saline solution, followed by nebulization of different concentrations of acetylcholine: 1, 2, 4, 8, 16, 32 and $64 \mathrm{mg} / \mathrm{kg}$.

All atomizations were held over a period of 30 seconds, by means of the ultrasonic nebulizer (Inalasonic ${ }^{\circledR}$ model, NS) coupled to the inspiratory mechanical fan branch. Soon after the nebulization, the impedance of the respiratory system $\left(Z_{r s}\right)$ was measured by forced oscillation technique in sequence at intervals of $30 \mathrm{~s}$ for 5 minutes.

\subsection{Statistical Analysis}

Results are presented as mean $\pm \mathrm{SD}$, where $n$ represents the number of samples. Data normal distribution and homogeneities of variances were tested with Kolmogorov-Smirnov (with Lilliefors's correction) and Levene median tests, respectively. If both conditions were satisfied, Student's t-test was used. If any condition was refused, Mann-Whitney non-parametric test was used instead. A difference was considered significant if $p<0.05$.

\section{RESUlts}

The results concerning the analysis of respiratory impedance $\left(Z_{r s}\right)$ are presented in Figure 2 . The values of the variables related to airway resistance $\left(R_{N}\right)$, the tissue elastance $(H)$ and $(G)$ of tissue resistance groups P10 and P30 compared to the control group were statistically significant. 


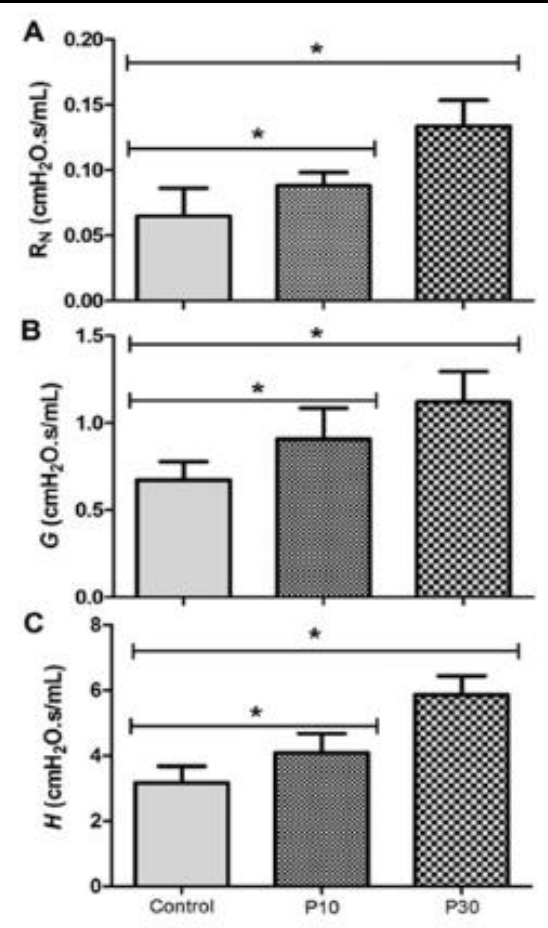

Fig2. Airway resistance $\left(R_{N}\right)$ in $A$, tissue resistance $(G)$ in $B$, and tissue elastance $(H)$ in $C$. values are represented by mean \pm standard deviation of the mean. *represents statistically significant values compared to the control group $(p<0.05)$.

The absolute values, for the calculation of the impedance of the respiratory system $\left(Z_{r s}\right)$, for purposes of calculating variables for $R_{N}, G$ and $H$, control groups, P10 (10 mg/kg of paraquat) and P30 (30 $\mathrm{mg} / \mathrm{kg}$ of paraquat), are shown in table 1.

Table1. Mechanical data of animals exposed to air and paraquat.Values are mean $\pm S D$. $* p<0.05$, statistically significant difference.

\begin{tabular}{|c|c|c|c|}
\hline Measure & Group & Value & pvalue $(\boldsymbol{t}$ student) \\
\hline & Control & $0.064 \pm 0.021$ & \\
Newtonian Resistence $\left(R_{N}\right)$ & P10 & $0.088 \pm 0.907$ & $p=0.0292^{*}$ \\
$\left(\mathrm{cmH}_{2} \mathrm{O} / \mathrm{mL}\right)$ & $\mathrm{P} 30$ & $0.133 \pm 0.019$ & $p<0.0001^{*}$ \\
& Control & $0.67 \pm 0.10$ & \\
Tissue Resistence $(G)$ & $\mathrm{P} 10$ & $0.90 \pm 0.17$ & $p=0.0064^{*}$ \\
$\left(\mathrm{cmH}_{2} \mathrm{O} / \mathrm{mL}\right)$ & $\mathrm{P} 30$ & $1.12 \pm 0.17$ & $p<0.0001^{*}$ \\
\hline & Control & $3.17 \pm 0.50$ & \\
Tissue Elastance $(H)$ & P10 & $4.08 \pm 0.59$ & $p=0.0068^{*}$ \\
$\left(\mathrm{cmH} \mathrm{H}_{2} \mathrm{O} / \mathrm{mL}\right)$ & $\mathrm{P} 30$ & $5.86 \pm 0.57$ & $p<0.0001^{*}$
\end{tabular}

The dose-response curve acetylcholine built with the objective of evaluating the hiperreatividade of the smooth muscle of the Airways is presented in Figure 3. The hiperresponsividade Airways is defined as an excessive narrowing of the Airways in response to a variety of chemical and physical stimuli that have little or no effect in healthy individuals (Brusasco et al., 2003).

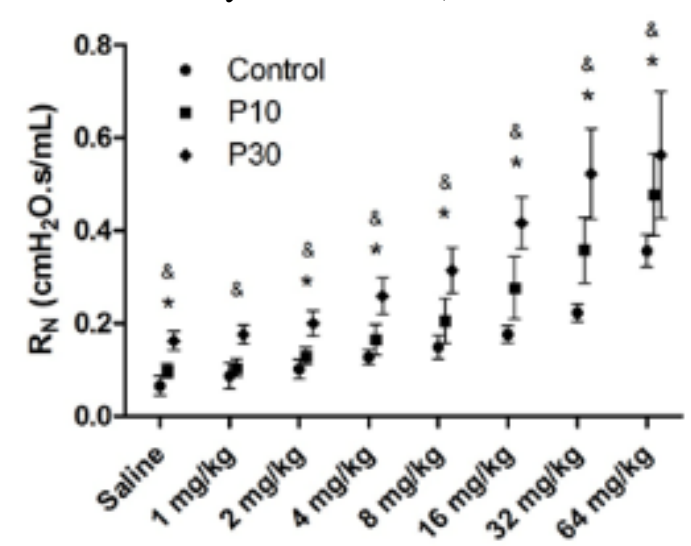

Fig3. Reactivity of the Airways. Values are mean $\pm S D$. $(*)$ P10 statistically significant difference $(p<0.05)$ and (\&) P30 statistically significant difference. 


\section{DISCUSSION}

Herbicides control weeds by interfering in how they grow. It is occurs by blocking the germination of seeds or seedlings, preventing the production of essential proteins, carbohydrates or lipids (oils and fats) by plants, or dehydrating their leaves and stems (Powles et al., 2006; Santra, et al., 2008). Paraquat acts in the process of photosynthesis. When solar energy is captured by chlorophyll, it is transferred into a stream of electrons through Photosystem I. Paraquat deflects this flow, which results in the production of free radicals, highly reactive, destroy cell membranes very quickly, pouring the contents manifesting itself as yellowing and dryness. Almost all green plants are affected by paraquat, which makes it a non-selective broad spectrum herbicide (Powles et al., 2006; Santra, et al., 2008).

The pesticide poisoning occurs, generally, by the lack of knowledge that they can penetrate the metabolism by direct consumption of food (fish, molluscs, crustaceans, beef, vegetables, legumes). Other times, the poisoning occurs due to misinformation of their symptoms and on ways of penetration, accumulation and transport of the poison in the human body, about what is the pesticide, and how do you get the product (Castro, 2009).

In relation to ours results, the Newtonian resistance $\left(R_{N}\right)$ has been used as a good estimate of the total airway resistance (Bates, 2009). Thus, it can be assumed that significantly larger values in P10 and $\mathrm{P} 30$, exposed to $10 \mathrm{mg} / \mathrm{kg}$ and $30 \mathrm{mg} / \mathrm{kg}$, compared to the control group, may represent a greater narrowing or increase in rigidity of airway smooth muscle. Increased airway resistance $\left(R_{N}\right)$ is due to a decrease in the internal diameter of the airway, which can be attributed to the presence of edema, fluid accumulation, broncoconstricção and/or lung volume reduction (Rocco, 2004).

The tissue resistance $(G)$ reflects the viscous dissipation of energy in the pulmonary tissue parameter that is also altered due to distortion of the lung parenchyma, this explains the significant increases in the values of $G$ and $H$ in the presence of paraquat, since there was a relation With the increase in the airway resistance parameter $\left(R_{N}\right)$. Exposure to paraquat generates physiological characteristics of acute lung injury (ALI) (Rocco et al., 2001). Collagen and other elastic components are increased in the ALI process due to a fibroelastosis process initiated early in the first $24 \mathrm{~h}$ of lesion evolution (Rocco et al, 2001). Exposure to paraquat can significantly induce the expression of connective tissue growth factor, which results in a process of pulmonary fibrosis (Huang et al., 2015).

The tissue resistance $(G)$ and the tissue elastance $(H)$ are related to the intrinsic properties of the fabric. There are several hypotheses to explain its alterations, one of which is due to the modification in the properties of alveolar surfactant and/or loss of lung capacity due to the presence of liquid on the alveolar surface (Gregory et al., 1991, Rocco et al., 2003). Another pathway is through the influence that the narrowing of the airways, resulting in what could be called a distortion of the lung parenchyma with the closure of small airways. In the first $24 \mathrm{~h}$, fluid accumulation occurs in the interstitium and in the air spaces of the lung, leading to hypoxemia, decreased pulmonary compliance and increased respiratory work (Rocco et al., 2003).

Bronchoconstrictors have been widely used in research of animals with lung inflammation because of the notion that the primary problem in asthma is the excessive shortening of smooth muscle airway, whether due to an exacerbation of smooth muscle response capacity itself (Fredberg et al., 1997), or by an increase in airway wall stiffness and thickness (Moreno et al., 1996; Wagers et al., 2004). There are several ways in which the lung can become hyperresponsive to bronchoprovocation, these include mechanisms by which the effect of smoothness of airway smooth muscle is amplified through geometric effects (Bates et al., 2007) and the mechanisms involving the Increased muscle shortening (Ding et al., 1987).

Measurement of airway responsiveness, with alterations in some airway pathologies, can be accomplished through the use of agonists that cause bronchoconstriction. It is well known that the action that a bronchoconstrictor causes on the $R_{N}$ variable, since it causes a contraction of the smooth muscle of the airways, which in turn leads to a narrowing of the airway lumen, thus increasing resistance to airflow, so that when the increase is excessive it is said that the smooth muscle is hyperresponsive (Bates, 2009). Rocco and collaborators (2003), after administration of $10 \mathrm{mg} / \mathrm{kg}$ (P10) and $25 \mathrm{mg} / \mathrm{kg}$ (P25) of paraquat, found an increase in polymorphonuclear cells in rat lungs in both groups when compared to the respective control. In addition, a significant increase of the inflammatory mediators in the P25 group could be observed when compared to the group P10. 
In the present study, the results showed a hyperresponsiveness of the airway smooth muscles of the animals of groups P10 and P30, in relation to the control group (Figure 3), confirming the effect of paraquat in the two dosages used. Several factors need to be taken into account in order to achieve precision on the factor that contributes to the excessive narrowing of the airways in situations of previous lung disease such as asthma. An excessive expression of myosin light chain kinase may be responsible for excessive narrowing of the airways as well as a change in length and integrity in the myosin or actin filaments or also a change in the composition of myosin chain isoforms in asthmatics (Xuefei et al., 2002).

Inflammatory mediators typically present in asthma may trigger abnormal narrowing of the airways, even when the tracheal smooth muscle is perfectly normal (Iipma et al., 2015). This fact may explain the excessive increases in airway resistance in the P10 and P30 groups containing paraquat, since the lung injury induced by this herbicide is characterized as a potentially fatal disease of respiratory failure due to an inflammatory response of the lungs (Tyagi et al., 2016).

\section{Conclusion}

The need to produce food for more than 7 billion people worldwide is one of the greatest challenges today. In the current model of production, the use of technology and agrochemicals are necessary to maintain adequate productivity and volume of production, where the use of agrochemicals involves biossocial, political, economic and socio-environmental aspects. However, due to the environmental and health problems generated by the uncontrolled use of pesticides, the use of other forms of production should be encouraged, with the reduction or absence of agrochemicals, such as organic and agroecological production. Public policies that encourage the growth of these alternative production methods are needed to value more sustainable forms of production. In conclusion, the results demonstrated the harmful character that exposure to paraquat can cause in the respiratory system of rats. The present work demonstrates the importance of the professional and adequate management of certain agricultural herbicides currently used to avoid further health complications and to reinforce the discussion about the conscious use of agrochemicals in the world food industry. More detailed studies are required that can quantify the level of exposure that the population undergoes when eating some foods, which may present remnants of this pesticide in its composition. Such an initiative can help to clarify the problem inherent in the unconscious ingestion of pesticides.

\section{REFERENCES}

Bates, J. 2009.Lung mechanics an inverse modeling approach. Cambridge University press.

Bates, J.H., andA.M. Lauzon.2007. Parenchymal tethering, airway wall stiffness and the dynamics of bronchoconstriction. Journal of Applied Physiology. 102(5):1912-1920. doi:10.1152/ japplphys iol.00980.2006

Brusasco, V., and R. Pellegrino.2003. Airway Hyperresponsiveness: From Molecules to Bedside Invited Review: Complexity of factors modulating airway narrowing in vivo: relevance to assessment of airway hyperresponsiveness. Journal of Applied Physiology. 95(2):1305-1313.

Castro, V.L.S.S. 2009. Uso de misturas de agrotóxicos na agricultura e suas implicações toxicológicas na saúde [Use of agrochemical blends in agriculture and their toxicological implications on health]. Journal of the Brazilian Society of Ecotoxicology. 4(1):87-94.

Cha, E.S., Y.H. Khang, and W. Lee. 2014. Mortality from and incidence of pesticide poisoning in South Korea: findings from national death and health utilization data between 2006 and 2010. Plos one. 9(4):e95299.doi: 10.1371/journal.pone.0095299

Chan, Y.C., S.C. Chang,S.L. Hsuan, M.S. Chien, W.C. Lee, J.J. Kang, S.C. Wang, and J.W. Liao. 2007. Cardiovascular effects of herbicides and formulated adjuvants on isolated rat aorta and heart. Toxicology in vitro. 21(4):595-603. doi:10.1016/j.tiv.2006.12.007

Chao, L.K., andT.E.C. Fang. 2016. Dialysis catheter-related pulmonary embolism in a patient with paraquat intoxication. Tzu chi medical journal. 28(4):166-169. doi:10.1016/j.tcmj.2015.05.005

Choi, J.S., S.S. Jou, M.H. Oh, Y.H. Kim, M.J. Park, H.W. Song, and S.Y. Hong. 2013.The dose of cyclophosphamide for treating paraquat-induced rat lung injury. The Korean Journal of Internal Medicine. 28(4):420-427. doi:10.3904/kjim.2013.28.4.420

Ding, D.J., J.D. Martin, and P.T. Macklem. 1987. Effects of lung volume on maximal methacholine induced bronchoconstriction in normal humans. Journal Applied Physiology.62(3):1324-1330. 
Forget, G., T. Goodman, and A. Villiers. 1993. Balancing the need for pesticides with the risk to human health. Acessed: 10/20/2016. Available in:https://idl-bnc.idrc.ca/dspace/bitstream/10625/ 18585/1/IDL-18585.pdf

Fredberg, J.J., R.H.J. Ingram, R.G. Castile, G.M. Glass, J.M. Drazen. 1985. Nonhomogeneity of lung response to inhaled histamine assessed with alveolar capsules. Journal of Applied Physiology.58 (6):1914-1922.

Gianessi, L. 2013. The increasing importance of herbicides in worldwide crop production. Society of chemical industry. 69(10):1099-1105. doi:10.1002/ps.3598

Gregory, T., W. Longmore, M. Moxley, J. Whistsett, C. Reed, A. Fowler, L. Hudson, R. Maunder, C. Crim, and T. Hyers. 1991. Surfactant chemical composition and biophysical activity in acute respiratory distress syndrome. Journal clinical investigation. 88(6):1976-1981. doi: 10.1172/JC I115523

Gunnel, D., M. Eddleston, M. Phillips, and F. Konradsen. 2007. The global distribution of fatal pesticide self-poisoning: Systematic review. BMC Public Health.7:1-15. doi:10.1186/1471-24587-357

Hantos, Z., B. Daroczy, B. Suki, S. Nagy, and J.J. Fredberg. 1992. Input impedance and peripheral inhomogeneity of dog lungs. Journal of Applied Physiology. 72(1):168-178.

Hirai, T., K.A. Mckeown, R.F. Gomes, andJ.H. Bates. 1999. Effects of lung volume on lung and chest wall mechanics in rats. Journal of Applied Physiology. 86(1), 16-21.

Huang, M., H.Z.L. Yang, H. Li, J. Zhou, and Z. Zhou. 2015. Inhibition of Connective Tissue Growth Factor Attenuates Paraquat-Induced Lung Fibrosis in a Human MRC-5 Cell Line. Environmental toxicology. 31(11):1620-1626. doi: 10.1002/tox.22166

Ijpma, G., L. Kachmar, O.S. Matusovsky, J.H. Bates, A. Benedetti, J.G. Martin, and A.M. Lauzon. 2015. Human Trachealis and Main Bronchi Smooth Muscle Are Normoresponsive in Asthma. American Journal of Respiratory and Critical Care Medicine. 191(8):884-893. doi: 10.1164/ rccm.201407-12960C

Kapsali, T., S.Permutt, B. Laube, N. Scichilone, and A. Togias. 2000.Potent bronchoprotective effect of deep inspiration and its absence in asthma. Journal Of Applied Physiology. 89(2):711-720.

Khaligh, Z., A. Rahmani, J. Cheraghi, M. Ahmadi, K. Soleimannejad, R. Asadollahi, and K. Asadollahi.2016.Perfluorocarbon attenuates inflammatory cytokines, oxidative stress and histopathologic changes in paraquat-induced acute lung injury in rats. Environmental toxicology and pharmacology. 42(1): 9-15. doi:10.1016/j.etap.2015.12.002

Martins, T. 2013. Herbicida paraquat: Conceitos, modo de ação e doenças relacionadas [Paraquat Herbicide: Concepts, Mode of Action and Related Diseases].Semina: Ciências biológicas e da saúde. 34(2):175-186. doi:10.5433/1679-0367.2013v34n2p175

Moreno, J.H., J.C.Y. Toledo, and F.A.H. Fonseca. 2004. Hipertensão refratária e tabagismo [Refractory hypertension and smoking]. Revista Brasileira de Hipertensão. 11(4):256-261.

Naito, H., andM. Yamashita. 1987. Epidemiology of paraquat in Japan and a new safe formulation of paraquat. Human toxicology. 6(1):87-88.

NHSA (National Health Surveillance Agency). Paraquat technical regulation. Acessed: 06/26/2010. Available in: http://www4.anvisa.gov.br/base/visadoc/CP/CP[18968-1-0].PDF

Powles, S.B., and C. Preston. 2006. Evolved glyphosate resistance in plants: biochemical and genetic basis of resistance. Weed Technology. 20(6):282-289.

Rocco, P.R., E.M. Negri, P.M. Kurtz, F.P. Vasconselos, G.H. Silva, V.L. Capelozzi, P.V. Romero, and W.A. Zin. 2001.Lung Tissue Mechanics and Extracellular Matrix Remodeling in Acute Lung Injury. American journal of respiratory and critical care medicine. 164(6):1067-1071. doi:10.1164/ajrccm.164.6.2007062

Rocco, P.R., L.D. Facchinetti, H.C. Ferreira, E.M. Negri, V.L. Capelozzi, D.S. Faffe, and W.A. Zin. 2004. Time course of respiratory mechanics and pulmonary structural remodelling in acute lung injury. Respiratory Physiology \& Neurobiology. 143(1):49-61. doi: 10.1016/j.resp.2004.06.017

Rocco, P.R., A.B. Souza, D.S. Faffe, C.P. Passaro, F.B. Santos, E.M. Negri, J.G. Lima, R.S. Contador, V.L. Capelozzi, and W.A. Zin. 2003.Effect of Corticosteroid on Lung Parenchyma Remodeling at an Early Phase of Acute Lung Injury. American journal of respiratory and critical care medicine. 168(6):677-684. doi:10.1164/rccm.200302-256OC 
Santra, S., and U. Baumann. 2008. Experience of nitisinone for the pharmacological treatment of hereditary tyrosinaemia type 1. Expert Opinion on Pharmacotherapy. 9(7):1229-1236.

Schmitt, G.C., C. Paniz, D. Grotto, J. Valentini, K.L. Schott, V.J. Pomblum, and S.C. Garcia. 2006. General aspects and clinical laboratorial diagnostic of poisoning by paraquat. Jornal Brasieleiro de Patololgia e Medicina Laboratorial. 42(4):235-243.

Serra. A., F. Domingos, and M. Prata. 2003. Intoxicação por paraquat [Paraquat poisoning]. Acta médica portuguesa. 16(1): 25-32.

Stephenson, G.R., I.G. Ferris, P.T. Holland, and M. Nordberg. 2006. Glossary of terms relating to pesticides (IUPAC Recommendations 2006). Pure and Applied Chemistry. 78(11):2075-2154.

Tian, Z.G., Y. Ji, W.J. Yan, C.Y. Xu, Q.Y. Kong, F. Han, Y. Zhao, and Q.F. Pang. 2014. Methylene blue protects against paraquat-induced acute lung injury in rats. International Immunopharmacology. 20(2):358. 2014. doi:10.1016/j.intimp.2013.06.022

TUIAP (Trade union of the industries of agricultural products). 2012. Situation of the agrochemicals market in the world and in Brazil. Available in: https://biowit.files.wordpress.com/2010/11/ cartilha-dados-sobre-agrotoxicos-mundo-brasil-maio-12.pdf

Tyagi, N., D. Dash, and R. Singh. 2016. Curcumin inhibits paraquat induced lung inflammation and fibrosis by extracellular matrix modifications in mouse model. Inflammopharmacology. 24(6):335-345. doi:10.1007/s10787-016-0286-z

Wagers, S., L.K.A. Lundblad, M. Ekman, C.G. Irvin, and J.H. Bates. 2004. The allergic mouse model of asthma: normal smooth muscle in an abnormal lung. Journal Applied Physiology. 96(6):20192027. doi:10.1152/japplphysiol.00924.2003

Xarau, S., and A. Laita. Intoxicatión por paraquat: un puzzle al que le faltan piezas [Paraquat intoxication: a puzzle that is missing pieces]. Medicina clínica. 115(14). doi:10.1016/S00257753(00)71619-8

Xuefei, M.A., C. Zhaoqin, K. Hong, W. Ying, U. Helmut, and L.S. Newman, L. Michel. 2002. Changes in biophysical and biochemical properties of single bronchial smooth muscle cells from asthmatic subjects. American Journal of Physiology. Lung Cellular and Molecular Physiology. 283(6):1181- 1189. doi:10.1152/ajplung.00389.2001

Zhang, Z.P. 2003. Development of chemical weed control and integrated weed management in China. Weed biology and management. 3(4):197-203. doi:10.1046/j.1444-6162.2003.00105.x 